\title{
"FAÇAMOS DESSA GENTE UM ELEMENTO SEGURO DO NOSSO PROGRESSO MATERIAL E MORAL": A INSPEC̣ÃO MÉDICO-ESCOLAR NO PARANÁ DOS ANOS 1920
}

\author{
Vera Regina Beltrão Marques* \\ Fabiana Costa de Senna Ávila Farias**
}

RESUMO: A linha norteadora da educação no Paraná está fundamentada na necessidade de recuperar o homem nativo (caboclo) enquanto força de trabalho através de seu aperfeiçoamento moral, físico, intelectual e laboral. Requer-se da escola o desempenho desta patriótica missão: formar a inteligência do caboclinho de maneira a conhecer intuitivamente preceitos da higiene, meios de defesa contra os insetos e animais nocivos, vantagens do calçado e do uso de instrumentos aperfeiçoados para maior rendimento do trabalho manual". Com essa escola, as autoridades educacionais acreditaram que a higiene rural encontraria o seu melhor auxiliar. Nossa comunicação discute as propostas de inspeção médico-escolar na gestão de Cezar Prieto Martinez, tendo em vista as singularidades populacionais e os objetivos de nacionalização da escola almejados. Que características e desdobramentos norteiam o discurso médico higienista em face da realidade na qual o embranquecimento não se coloca como questão fundamental?

Palavras-chave: Higiene; Escola; Inspeção Médica.

\footnotetext{
* Doutora em História Social pela Universidade Estadual de Campinas (UNICAMP); Pós-Doutora pelo Centro de Pesquisa em História Social da Cultura da Universidade Estadual de Campinas (CECULT/UNICAMP); Professora Associada na Universidade Federal do Paraná e no Programa de Pós-Graduação em Educação (linha de pesquisa: História e Historiografia da Educação da Universidade Federal do Paraná (UFPR).E-mail: verabm@ufpr.br

** Mestranda em Educação (linha de pesquisa: História e Historiografia da Educação) na Universidade Federal do Paraná (UFPR).
} 


\section{LET'S MAKE THESE PEOPLE A SAFE ELEMENT OF OUR MATERIAL AND MORAL PROGRESS: MEDICAL-SCHOLAR INSPECTIONS IN PARANÁ DURING THE 1920'S}

ABSTRACT: The main axis of Education in Paraná is based on the necessity of retrieving the native man (half-caste) as labor force by the development of their moral, physic, intellect and work. This way, it is expected from the school, such patriotic mission: to develop the little native men intelligence in order to make them intuitively aware of "the most appropriate hygiene practices, defensive attitudes against insects and harmful animals, and the advantages of wearing shoes and utilizing improved tools for better handiwork". With such school, educational authorities believed that rural hygiene would find its best supporter. This communication intends to discuss proposals of medical-scholar inspections presented during Cesar Prieto Martinez's public management, taking into consideration the specificities of the population and the objectives of the school nationalization aimed by the State. What characteristics and developments guide medical hygienist discourse in relation to such reality, which had not the "white becoming" as its main question?

Keywords: Hygiene; School; Medical-Scholar.

A lei n. 2095, de 31 de março de 1921, criou no Paraná o serviço de inspeção médica nas escolas, funcionando anexo à Inspetoria Geral do Ensino. Pautado na experiência adquirida em São Paulo, Cezar Prieto Martinez pretendia fazer da sua gestão frente à Inspetoria Geral um modelo, elegendo a higiene sua pedra de toque. "Assistir a infância, em geral, é medida de elevado alcance patriótico, pois a infância crescendo robusta no físico e no moral promete à nação um povo forte", pregava Prieto. O Paraná, cuja autonomia fora conquistada somente em 1853, necessitava impor-se frente à nação, e instruir o povo, proporcionando escola pública primária gratuita, tornara-se fundamental (VECHIA, 2004). Ademais, existiam em todo o estado muitas escolas estrangeiras "como se funcionassem em território estrangeiro", "desnacionalizando a infância" e os filhos do Paraná brasileiro. O foco das atenções voltou-se para as crianças. Crianças criadas como se em outra pátria estivessem deveriam ser nacionalizadas por meio da educação, pois "dois problemas capitais exigem pronta solução: a higiene e a escola primária; deles depende o futuro do Brasil".

Normas de bem viver com saúde, ensinadas aos professores de modo a desempenhar a contento seus papéis de mestres, reverteriam em novos hábitos nos alunos, então "em completo estado de desasseio, tanto do corpo como das vestes, sem falar na falta de cuidado com os cabelos, unhas, dentes e pés" (Relatório do Inspetor Geral, 1921). 
As escolas offerecem tristonho aspecto. A creançada, no geral, é muito pouco desenvolvida, apparentando metade da edade que tem. Os semblantes assignalam uma tristeza doentia. A frequencia ás aulas é irregularissima. Em muitos casos são mais numerosas as faltas que os comparecimentos. O aprendizado realisa-se, por esse facto, morosamente. (Relatório do Inspetor Geral, 1923)

Assim sendo, uma das primeiras medidas da nova Inspetoria consubstanciou-se em demandar um curso de higiene para os professores.

"A convite do sr. Professor Cezar Prieto Martinez, digno inspetor geral do Ensino no Paraná, e com a aprovação e prestígio do governo do Estado, o sr. Dr. Heráclides César de Souza Araújo, chefe do Serviço de Profilaxia Rural e redator-chefe desta revista [Arquivos Paranaenses de Medicina] criou um curso elementar de Higiene, destinado aos professores públicos do Paraná, tendo se realizado a aula inaugural, no dia 15 deste mês [setembro], às 18 horas, no salão nobre do Ginásio Paranaense" (Arquivos Paranaenses de Medicina, 1920-1, ano I, p. 144).

O Dr. Marins Camargo, Secretário Geral do Estado, frisou a importância de se difundirem em larga escala os conhecimentos de higiene, "preparando-se desse modo o nosso povo para conhecer o perigo das moléstias e assim poder evitá-lo". Saudou com entusiasmo a obra de saneamento em curso no Paraná e "estimulou os professores públicos a se interessarem pelos assuntos de higiene geral, que lhes seriam desvendados", pois assim poderiam propagar as "boas idéias" entre seus discípulos (Arquivos Paranaenses de Medicina, 1920-1, ano I, p. 145).

O curso, organizado em duas partes, abarcava temas teóricos e aulas práticas. Era gratuito e ministrado por médicos ligados ao serviço do estado. Entre os quinze pontos apresentados teoricamente constavam: 1) noções gerais sobre higiene, importância do saneamento do Brasil, ofidismo; 2) micro-organismos patogênicos em geral, infecção, defesas do organismo, penetração do agente infeccioso, evolução e especificidade das infecções, vacinação e soroterapia; 3) doenças contagiosas em geral, meios de contágio, animais transmissores de doenças: mosquitos, barbeiros, pulgas, piolhos, etc.; 4) ectoparasitoses, noções gerais sobre a escabiose, a pediculose, as tinhas, etc. e sua profilaxia; 5) verminoses intestinais e noções teórico-práticas sobre a ancilostomose, ascaridiose, tricuriose, etc. e sua profilaxia; 6) febres eruptivas, noções gerais sobre a escarlatina, o 
sarampo e o grupo variólico. Profilaxia e vacinação antivariólica; 7) tracoma, raiva e moléstia de Heine-Medin, noções gerais e sua profilaxia, vacinação antirrábica; 8) infecções tíficas e paratíficas, desinterias com noções teórico-práticas e profilaxia; 9) difteria, tétano e meningite cérebro-espinhal com noções teórico-práticas e profilaxia; 10) tuberculose com noções teórico-práticas e profilaxia; 11) lepra e sua profilaxia; 12) epizootias transmissíveis ao homem, como peste, mormo e carbúnculo; 13) impaludismo e noções teórico-práticas sobre diversos parasitos: doença de Chagas e leishmaniose e profilaxia; 14) doenças venéreas, como sífilis e blenorragia, e profilaxia; e a última aula da parte I, que versava sobre intoxicações provocadas por morfina, cocaína, álcool e alcoolismo, com considerações médico-sociais e profilaxia. A parte II tratava de higiene escolar e alguns pontos de medicina social.

O curso foi frequentado por " 65 professores públicos além de muitas outras pessoas, entre as quais alguns professores do Ginásio Paranaense". No correr das aulas, foram realizadas "sabatinas" assistidas por Prieto Martinez e pelo diretor do Ginásio Paranaense e Escola Normal. Vários "lentes" desses estabelecimentos de ensino adrede inspetores escolares, representantes da imprensa e numerosas pessoas graduadas também faziam parte dos espectadores dessa prova, elogiada pelo Sr. Secretário Geral do Estado em nota no jornal, nominando as professoras que se submeteram às sabatinas.

Terminado o curso, foi aplicado o exame final, realizado por 28 professoras, e o certificado de frequência e aproveitamento foi concedido a 27 delas. As primeiras classificadas receberam prêmios conferidos pelo governo estadual (Arquivos Paranaenses de Medicina, 1921, n. 11). A nota para aprovação somava 9,0 pontos e os inabilitados receberam somente atestado de frequência (Arquivos Paranaenses de Medicina, 1920, n. 1).

Porém, o número de aprovados indica que possivelmente nem todos os professores tivessem cabedal intelectual ou ainda tempo para acompanhá-lo com dedicação. Assim, parte dos anseios do Serviço de Profilaxia Rural não se efetivava, pois não se contaria com tantos professores a divulgar a moderna saúde pública.

Instruídos os professores, mais fácil ficaria identificar os alunos acometidos pelas várias doenças que concorriam para a evasão escolar, entre as quais destacavam-se as verminoses, as anemias, as pediculoses, os casos de "heredo lues", a tuberculose ou as epidemias de varicela, 
sarampo, coqueluche, gripes e escarlatina, frequentes nas escolas. Médicos e professores não tinham dúvidas: somente com higiene haveria condições de saúde adequadas e "escola produtiva", pois, sem vigor físico, os alunos jamais se tornariam futuros cidadãos moralizados e úteis ao estado e à nação. Fazia-se do professor um aliado imprescindível para levar a cabo a cruzada higienizadora.

\section{A inspeção médico-escolar: espaço cruzado de médicos e professores}

Constituir futuros cidadãos saudáveis e produtivos implicava conter alguns males oportunizados pela própria organização escolar. A aglomeração durante as aulas gerada pela concentração de crianças em espaços diminutos, sem ventilação e iluminação adequadas, já se constituía em fator de risco. Porém, havia mais a considerar: as doenças que são características da faixa etária e aquelas decorrentes da atividade escolar propriamente dita. Assim, manuais e procedimentos visando à proteção e ao cuidado com os rebentos nas escolas primárias procuravam delinear práticas e novas configurações para o espaço escolar, que, por intermédio do professor, revestiam-se em meios a auxiliar na profilaxia dos alunos, tarefa essa incorporada ao fazer pedagógico.

O caboclinho deve formar a sua intelligencia á luz de uma intelligencia bem esclarecida, de maneira a conhecer intuitivamente quaes os preceitos mais exigentes da hygiene, meios de defeza contra os insectos e animaes nocivos, perigos que offerece o alcool; vantagens do calçado... (Relatório do Inspetor Geral, 1923)

Mas havia alguns complicadores para a efetivação desse empreendimento: muitos professores continuavam a desconhecer os assuntos relacionados à higiene e à profilaxia, não sabendo lecionar sobre os conteúdos. Quando estes aconselhavam os seus alunos a procurarem os postos profiláticos e a seguirem as prescrições médicas, alguns pais proibiam os filhos de aceitar tais medicações, alegando que os remédios fariam mal, ao invés de curarem. Um fato curioso é relatado por Prieto:

Approximavamos-nos de uma escola, cujas creanças estavam em recreio, no campo. Quando o nosso automóvel, deixando a estrada geral, dobrava á 
esquerda para ganhar o edifício izolado, a pequenada fugiu espavorida. Extranhamos essa precipitação, pois já eramos conhecidos dos alumnos e quando apeamos e fomos ao seu encontro para inqueril-os, alguns, mais corajosos, puderam fallar, sem occultar, comtudo, o susto que levaram:

- Pensamos que era o medico que nos vinha vaccinar...

- E que mal havia nisso?

- Todos dizem que a vaccina mata... (Relatório do Inspetor Geral, 1921, p. 52)

Mas não eram apenas os pais que manifestavam resistência. Mario Gomes, médico escolar, chegou a ponto de declarar: "julgo tambem necessaria uma lei obrigando as professoras á vaccinação antivariolica, pois encontrei mais de uma que se negou a vaccinar-se, determinando o máu exemplo, actos de indisciplina nos alumnos das respectivas classes" (Relatório do médico-escolar, 1923, p. 273). ${ }^{2}$

Com o intuito de propagar cada vez mais ideias em relação aos métodos de ensino, bem como indicar medidas que influenciassem especialmente a criança, quer quanto à sua saúde quer quanto ao seu caráter, a Inspetoria Geral de Ensino do Paraná publicaria, a $1^{\circ}$ de Janeiro de 1922, o primeiro número de $O$ Ensino, revista que sairia à luz trimestralmente. ${ }^{3}$

Eram também distribuídos os seguintes folhetos do Serviço de Profilaxia Rural: "Guerra ás Pulgas", do Dr. Barros Barreto, "Porque devemos combater os piolhos", do Dr. Leal Ferreira, e "O perigo dos mosquitos", do Dr. Luiz Medeiros, além da propaganda contra os pés descalços, aconselhando o uso de sapatos como medida de higiene e decência.

O primeiro livro de Noções de higiene para uso das escolas, de Afrânio Peixoto, professor da Faculdade de Medicina do Rio de Janeiro, e Graça Couto, diretor dos Serviços de Profilaxia e Desinfecção e diretor geral interino de Saúde Pública do Rio de Janeiro, publicado em 1914, expõe a inspeção médica das escolas como vigilância sanitária do meio escolar e dos alunos individualmente, e propõe formas de prevenção objetivando prevenir doenças transmissíveis. Noções essas que, no Paraná, procuravase seguir a contento.

A vigilância do meio escolar prendia-se aos aspectos físicos e higiênicos dos prédios no que tange à distribuição de mobiliário, ao arejamento, à iluminação, ao asseio e à ordem. Eram vistas como deploráveis: as construções escolares que apresentassem salas retangulares, 
estreitas e compridas e com uma distância grande entre os alunos da última fileira de carteiras e o quadro-negro, o que os obrigaria a um esforço prejudicial; escassez de água, ausência de filtros, falta de recreios protegidos, pátios úmidos, instalações sanitárias insuficientes no interior dos prédios ou em contiguidade às salas de classe, e paredes divisórias de madeira, que além de não estéticas e anti-higiênicas, seriam inconvenientes por transmitirem ruído, perturbando as aulas (Relatório do Serviço de Inspeção Médico-Escolar, 1921).

Segundo a Inspetoria, uma sala de aula deveria ter o espaço necessário para 25 carteiras duplas, a mesa do professor e uma área entre esta e a primeira fila de carteiras, a fim de que a turma de alunos chamados ao quadro pudesse ficar, sem aperto, distribuída em arco de círculo; a iluminação deveria ser unilateral ou bilateral, sempre harmônica e de sorte que a classe, convenientemente disposta, pudesse recebê-la da esquerda somente, ou da esquerda e de cima, ou ainda da esquerda e da frente. Cada sala deveria ter saída para um corredor espaçoso, onde as classes pudessem mover-se desembaraçadamente, e esses corredores fariam comunicar todas as salas entre si (Relatório do Serviço de Inspeção MédicoEscolar, 1921).

Normalmente, uma casa de ensino considerada de aspecto agradável era aquela em que havia "a Bandeira do Brasil hasteada na sala de aula, o Hymno Nacional cantado com enthusiasmo pelas meninas, uma bella exposição de trabalhos de agulha, o asseio, a ordem, a disciplina, etc", como ocorria na Escola Serro Azul, referenciava Prieto (Relatório do Inspetor Geral, 1923, p. 41).

Já a vigilância dos alunos estendia-se dos "conhecimentos de suas condições pessoais "em relação ao rosto, olhos, dentes, cabelos, mãos, unhas, pés, roupa, sapatos, chapéu, bolsa e livros, até a "prevenção de perigos possíveis para a coletividade escolar", como as moléstias e afecções infecto-contagiosas. Essa atenção incluía o exame antropológico, que media o grau de desenvolvimento físico, o exame fisiológico, avaliador da capacidade visual e auditiva, e o exame geral, no qual o médico detinha-se em "conhecer a regularidade de disposição dos órgãos e exercício das funções, principalmente desenvolvimento ósseo e muscular; adenopatias, vegetações adenóides, sinais de vício ou propensão tuberculosa" (PEIXOTO; COUTO, p. 416-417). Esses dados coletados compunham a caderneta sanitária do aluno, cujas anotações deveriam ser 
preenchidas ao ingressar no curso, uma ou duas vezes durante seu desenrolar e, finalmente, ao seu término. Claro que, no caso de "alunos predispostos, tarados ou enfermiços, compatíveis com a escola, serão examinados mais amiudadas vezes", diziam os higienistas para garantia própria e alheia (MARQUES, 1994) 4

Cezar Prieto Martinez, ao vir para o Paraná, talvez já conhecesse os livros de Balthazar Vieira de Mello relativos à higiene escolar publicados em São Paulo. Intitulados A bigiene na escola (1902) e Higiene escolar e pedagógica (1917), esses compêndios possivelmente apontaram "as linhas mestras", no dizer de Rocha (2005), a orientar e implantar serviços dessa natureza na Paulicéia. Ao que tudo indica, tenham sido de grande valia aqui também, embora não constassem na biblioteca organizada para dar amparo às atividades pedagógicas. ${ }^{5}$

O certo é: a revista do aluno, realizada por meio de exames médicos, compunha o espaço da vigilância em que o olhar observador levanta conhecimentos sobre ele. Apontados esses conhecimentos, documentados os vícios, registradas as aptidões e as degenerescências, formulam-se as comparações, classificações e categorizações para a fixação de normas e códigos médicos escolares, com o intuito de mantê-los sob controle e em conformidade com os comportamentos tidos como normais. Ademais, o coletivo de informações colhidas pode ser distribuído "na população escolar", especificando "casos" que poderão ser normalizados ou excluídos (MARQUES, 1994, p. 113). ${ }^{6}$

Essas inspeções, que, inicialmente, tinham caráter de polícia médica, em consonância com a medicina social da época - autoridade que intervinha, fiscalizava e punia -, foram criando as bases para a implantação da inspeção médica escolar disciplinar (MACHADO, 1978), com vistas a forjar a consciência sanitária que se propunha imprimir. Dos prédios e instalações físicas passava-se a intervir nos corpos, nos hábitos e nas consciências dos escolares, sob o advento da medicina social.

A escola tornava-se então "espécie de aparelho de exame ininterrupto", no dizer de Foucault, aliando as técnicas do exame pedagógico àquelas do exame de saúde, reforçando as técnicas da hierarquia que estabelece vigilância àquelas da sanção normalizadora. $\mathrm{O}$ exame antropopedagógico delegou ao professor determinada tarefa na técnica do exame, mas o fez estabelecendo um papel subordinado, seguindo um "ritual de poder constantemente renovado" (FOUCAULT, 1983, p. 166). 
Não foi em vão que a antropometria e a psicometria (como aplicações da biologia e da psicologia experimental ao âmbito escolar) se constituíram nas ciências por excelência da educação, e as fichas e os exames antropométricos e psicométricos, junto com as cadernetas sanitárias, no instrumento a partir do qual se toma toda e qualquer decisão sobre o futuro do escolar. (BAÑULLS, 2000, p. 76)

No Paraná, a Inspetoria Geral de Ensino comemorava, no relatório de 1922, os feitos das inspeções médicas: todos os grupos da capital haviam sido inspecionados, assim como os localizados em Paranaguá, Antonina, Morretes, Ponta Grossa e Castro, contabilizando 16, além das 18 escolas isoladas. Assim, 5308 alunos foram inspecionados, tendo sido expedidos 185 boletins e 552 receitas, além de organizadas 60 fichas de inspeção. Tornou-se até necessária a contratação de mais um médico ajudante ( $O$ Ensino, ano 2, n. 2, p. 171).

Ademais, a técnica do exame conferia aos médicos inspetores "a vistoria" dos empregados das escolas, fossem eles lentes, professores auxiliares ou candidatos aos cargos em aberto, fazendo do universo escolar objeto do saber e do poder médico.

\section{Doenças que degradam a espécie: degeneração à vista}

Nem mesmo o grande Beethoven ficara imune às doenças da hereditariedade.

Uma otite veda-lhe a audição. O mal que, como uma ironia brutalissima da sorte, lhe inutilisava desta fórma o orgam predestinado ás conquistas de sua arte, esse mal, de que nunca mais poude livrar-se, era a brusca revelação de uma tára congenita, com que o filho infeliz pagava os desregramentos da vida do pae.

E quantos escolares não partilhariam a mesma sina nas terras do Paraná?

A se considerar as imagens persistentes no início do século XX, de uma brasilidade plasmada nos excessos da carne e na volúpia do sexo, males, feito a sífilis, relacionados à sexualidade promíscua, adquiriam o estatuto de flagelos a atacar. Como afiançava Oscar Fontenelle, médico, advogado, político, ex-chefe de polícia, professor da Faculdade de Medicina do Rio de Janeiro, 
um mal, como refere certo autor falando da sífilis que alcança seguramente um terço da população adulta um mal, cujos acidentes terciários são mortais; um mal que com freqüência acarreta a esterilidade e que pode transmitir-se aos descendentes, seja sob forma infecciosa, rapidamente letal, seja sob forma de taras tão numerosas como variadas, das quais as mais ligeiras aniquilam o valor moral daqueles que são por elas atingidas, ao passo que as mais acentuadas comprometem a sua vida; um mal que faz recair sua nefasta influência, pelo menos, até sobre a terceira geração e talvez mais longe ainda; um mal dessa ordem tende, sem duvida a destruir o indivíduo tanto quanto a raça, é um mal social evidente incontestável", e complementa: "se a importância social das doenças venéreas foi tão longamente desconhecida, é que se ignoravam as taras extensas que infligiam aos indivíduos e à sua descendência. (FONTENELLE, 1931, p. 17-18)

O médico aludia à distribuição generalizada da doença, demarcando seu efeito mais avassalador: a destruição da raça - periculosidade que dizia respeito diretamente às implicações da herança transmitida de geração a geração. Mal tamanho incorporado como "de família"; consanguinidade adquirida, degeneradora dos futuros filhos; os filhos da família, os filhos da nação. Fruto do comportamento inadequado, impensado de uns a se refletir na estirpe, na prole, na sociedade.

Assim, conter a sífilis tornara-se vital. O Dr. Godinho, que, em 1923, assumira a chefia do Dispensário Anti-sifilítico de Curitiba, não titubeava: caminhava-se "a passos largos para uma era em que a escola", ministrando, desde a mais tenra idade, os primeiros ensinamentos sexuais, possibilitaria à criança "conhecer o imenso perigo das doenças venéreas e os meios de evitar a sua contaminação" (APM, 1923, p. 20). Complementando-o, o Dr. João de Barros Barreto afirmava que "a educação sexual deveria começar na escola primária, ampliando-a progressivamente, de conformidade com o desenvolvimento intelectual e físico da criança” (APM, 1923, p. 406).

A sífilis situava-se no cerne das discussões eugênicas, atendendo ao desideratum de Renato Kehl ${ }^{8}$ ao afirmar:, "é crime contra a civilização o descuido da geração de amanhã! Os governos têm moralmente a obrigação de zelar pelo futuro da raça, pela qualidade dos homens, pela saúde da população". Essa configuração do sexo como "capital patológico da espécie" foi enfrentada com propostas médico-políticas que transitavam do controle eugênico sobre a população ${ }^{9}$ às propostas de prevenir as doenças sexualmente transmissíveis, por meio da educação 
sexual a ser ensinada, preferentemente nas escolas, como apregoavam os esculápios paranaenses (MARQUES, 2004). Propostas que, efetivadas ou não, nos anos 1920, encontravam no espaço escolar importante lócus de difusão de conselhos higiênicos alicerçados na interdição do sexo até o casamento, máxima aconselhada por higienistas e professores, no escopo de conformar a vontade sexual do alunado mantendo a higidez física tão almejada ${ }^{10}$, fosse dos filhos imigrantes ou do caboclinho paranaense.

A considerar a população do estado, composta de número expressivo de imigrantes europeus ${ }^{11}$, compreende-se por que, no Paraná, a eugenia matizava-se, enveredando especialmente pelo controle das doenças, ditas degeneradoras da raça.

Embranquecer a população, diferentemente de outros locais, não se colocava como a saída para fazer dos paranaenses sujeitos eugenizados, aptos a construir o estado recentemente autônomo e a nação republicana. Eugenizar à moda paranaense significava higienizar a raça naquilo que dissesse respeito à contenção das doenças deformadoras da boa geração e ao depauperamento biológico dos $\operatorname{corpos}^{12}$. Então, como dizia o professor Menelau Torres, diretor da Escola Normal de Ponta Grossa, todos os esforços dos governos poderiam escoar pelo ralo abaixo, caso as populações ignorantes não adotassem as medidas preventivas e terapêuticas aconselhadas (O Ensino, ano 3, n. 1, p. 69). Assim, sífilis, doenças mentais, deficiências visuais ${ }^{13}$, doenças parasitárias ou infectocontagiosas mereciam destacado cuidado, pois implicavam o "abastardamento" da raça. ${ }^{14}$

Paradoxalmente, os imigrantes representaram tanto a salvação quanto a sentença condenatória, caso não fossem tratados e educados nos valores cívicos do país. Isso porque o "sangue regenerador" trazido por esses imigrantes brancos circulava em corpos de pessoas pobres, de hábitos "duvidosos" do ponto de vista higiênico, podendo espalhar a doença física e social. E, mais, mister se fazia constituir o caráter paranaense e brasileiro desses filhos, ainda carecendo nacionalizar-se. Não era à toa que Prieto festejava quando, ao visitar as escolas nas quais estudavam crianças filhas de imigrantes, as encontrava sendo alfabetizadas em português. Como salientava:

... já se vae notando uma accentuada differença no ensino das escolas polonezas. As religiosas empenham-se por aprender a nossa lingua, os livros nacionaes começam a ser lidos, os nossos hymnos patrioticos começam a ser 
cantados, a nossa Bandeira já figura nas salas de aula, os disticos em polaco principiam a dar logar a outros em portuguez, os feriados nacionaes já são respeitados. (Relatório do Inspetor Geral, 1923, p. 81)

Ou ainda, após visita de inspeção ao colégio da povoação de Ivahy, relatou:

Examinei livros e cadernos: tudo em portuguez. Conversei com a creançada: ninguem deixou de me responder... Quando, depois de ter ouvido o Hymno Nacional que encerrou o trabalho de minha inspecção, e assistido a reza das creanças em muito bom portuguez, me despedi, manifestando o meu contentamento pelo que acabava de ver, a freira directora da casa me pediu que lhe enviasse uma Bandeira do Brasil, para ser conhecida das creanças, bandeira que se hastearia na fachada do edificio em todos os dias de festa nacional.

Este facto, por si só, revela a conquista nacionalisadora que se vae realisando no seio das escolas particulares regidas por professores extrangeiros. (Relatório do Inspetor Geral, 1923, p. 82)

Demandavam ainda atenção especial os caboclinhos paranaenses e seus males, descritos por Mario Gomes em analogia ao sertanejo nacional. "São males antigos e atuais, que continuam solapando o já enfraquecido e desairoso especimem de nosso sertanejo, do cabloco litoranio, da grande massa do povo nacional (Revista Médica do Paraná, n. 1, 1932, p. 17) ${ }^{15}$. E Mario Gomes conhecia-os bem, pois andara muito pelo interior quando exercera a função médico-escolar.

O caboclinho paranaense, como as demais populações rurais brasileiras, despertou a atenção das autoridades e dos homens preocupados com os destinos da república quando, ao iniciarem-se as incursões pelo interior, pelos sertões do país, revelou-se o brasileiro depauperado que habitava o interior. Uma das pioneiras e mais notáveis, a viagem de Arthur Neiva e Belisário Penna, realizada em 1912, por vários estados do nordeste e centro-oeste, não deixou dúvidas: havia que enfrentar as agruras que acompanhavam as formas empobrecidas de viver, as doenças e a ignorância que grassava por toda parte ${ }^{16}$.

O caboclinho a que se referia o Dr. Gomes era, pois, o filho do sertanejo resultante da miscigenação do branco com o indígena ${ }^{17}$, e constituía o nativo, o caboclo do interior, a inspirar cuidados, pois carecia ser "melhorado". Se não trazia tanto "prejuízo" para a raça quanto aquele oferecido pelos ex-escravos, os quais era necessário "embranquecer", 
como enfatizava Renato Kehl, havia que livrá-los de suas doenças. De hábitos rurais, ditos ignorantes, precisavam ingressar nas formas consideradas civilizadas de viver e produzir. Ao alfabetizá-los, seriam educados na higiene e na eugenia e, uma vez recuperados de suas doenças, trabalhariam e produziriam mais e melhor. Aperfeiçoado física, moral, intelectual e laboralmente pela escola, pronto estaria o caboclinho para (re)conhecer intuitivamente "os preceitos mais exigentes da hygiene, meios de defeza contra os insectos e animaes nocivos, perigos que offerece o alcool, vantagens do calçado e do uso de instrumentos aperfeiçoados para maior rendimento do trabalho manual" (Relatório do Inspetor Geral de Ensino, 1921), em suma, apto a ingressar nas fileiras do trabalho disciplinado e produtivo.

A escola apresentava um poder de fogo ampliado em comparação às outras instituições, mesmo se comparadas aos dispensários de saúde. E a inspeção médico-escolar demonstrava às autoridades educacionais e sanitárias sua missão redentora ${ }^{18}$, oferecendo ao Paraná e "à Pátria os meios efficazes para nacionalizar [e recuperar] seus próprios filhos, energias dispersas, as quaes, intelligentemente guiadas, constituirão força prodigiosa de incalculável valor economico e cívico [...] façamos dessa gente um elemento seguro do nosso progresso material e moral", como assinalava Cezar Prieto Martinez, valendo-se da alfabetização e da higiene.

\section{Referências}

Arquivos Paranaenses de Medicina - APM 1920, 1921, 1923.

Fundo Monteiro Lobato - Séries de correspondências ativa e passiva.

Relatórios do Inspetor Geral do Ensino ao Secretário Geral do Estado, Marins Camargo - 1920-1923.

Relatórios da Inspeção Médico-Escolar - 1920 - 1923.

O Ensino, anos 1, 2 e 3, v. 1-4.

BAÑUELOS, AT. La higiene escolar: um campo de conocimiento disputado. Áreas, Revista de Ciências Sociales, n. 20, 2000.

BASILE, P. Inspeç̧ão medica escolar. São Paulo, Tese inaugural. Faculdade de Medicina e Cirurgia de São Paulo, 1920.

BERTUCCI, L. M. Educação e saúde para formar o povo brasileiro. In: DINIS, N.F. e BERTUCCI, L. M.(Orgs.). Múltiplas faces do Educar: processos de aprendizagem, educação e saúde, formação docente. Curitiba: Editora UFPR, 2007.

CARVALHO, J.M. Os bestializados: o Rio de Janeiro e a República que não foi. São Paulo, Companhia das Letras, 1987.

CHALHOUB, S. Cidade febril: cortiços e epidemias na corte imperial. São Paulo: 
Companhia das Letras, 1996.

FOUCAULT, M. Microfísica do poder. Rio de Janeiro: Graal, 1981.

FOUCAULT, M. Vigiar e punir: nascimento da prisão. Petrópolis: Vozes, 1983.

FONTENELlE, O. A eugenia. Arquivos Paranaenses de Medicina, ano IV, 1923.

KEHL, R. Lições de engenia. Rio de Janeiro: Francisco Alves, 1929.

LIMA, N.T.; HOCHMAN, G. Absolvido pela medicina: o Brasil descoberto pelo movimento sanitarista da Primeira república. In: MAIO, M.C.; SANTOS, R.V. (Orgs.). Raça, ciência e sociedade. Rio de Janeiro: Fiocruz, 1996.

MACHADO, R. et. al. Da(n)ação da norma: medicina social e constituição da psiquiatria no Brasil. Rio de Janeiro: Graal, 1978.

MARQUES, V.R.B. A medicalização da raça: médicos, educadores e discurso eugênico. Campinas: Unicamp, 1994.

MARQUES, V.R.B. A espécie em risco: sífilis em Curitiba nos anos 1920. In: NASCIMENTO, D.R.; CARVALHO, D.M. (Orgs). Uma história brasileira das doenças. Brasília: Paralelo 15, 2004.

MARQUES, V.R.B.; FARIAS, F.S.A. A inspeção médico-escolar no Paraná dos anos 1920: o apostolado de médicos e professores. In: DINIS, N.F.; BERTUCCI, L.M. (Orgs.). Múltiplas faces do Educar: processos de aprendizagem, educação e saúde, formação docente. Curitiba: Editora UFPR, 2007.

PEIXOTO, A; COUTO, G. Noções de bygiene- para uso das escolas. Rio de Janeiro: Liv Francisco Alves, 1914.

PEREIRA, M. R. M. Semeando iras rumo ao progresso. Curitiba: Editora da UFPR, 1996.

ROCHA, H.H.P. Escolarização, higienização e modernidade. Anais do III Congresso Brasileiro de História da Educação. Curitiba, CD-ROM, 2004.

SEVCENKO, N. A revolta da vacina: mentes insanas em corpos rebeldes. São Paulo: Brasiliense, 1984.

VECHIA, A. O plano de estudos das escolas públicas elementares na Província do Paraná. Revista Brasileira de História da Educação, n. 7, jan-jun., 2004.

WESTPHALEN, C.; MACHADO, B; BALHANA, A Nota prévia ao estudo da ocupação da terra no Paraná moderno. Curitiba: UFPR, 1968.

\section{Notas}

1 Segundo o discurso médico, todos os que não se desenvolviam física ou mentalmente a contento, como cretinos, perversos sexuais, aleijões ou desequilibrados, couberam na rubrica heredo-sifilíticos, abarcando todo e qualquer "desvio".

2 A resistência à vacina antivariólica no Rio de Janeiro está estudada em vários trabalhos. Destaco: Cidade febril, de Sidney Chalhoub, A revolta da vacina: mentes insanas em corpos rebeldes, da Nicolau Sevcenko, e Os Bestializados, de José Murilo de Carvalho. Em São Paulo também houve resistência, embora não tenha acontecido uma revolta nos moldes da ocorrida na capital federal.

3 O Ensino esclarecia que em relação à inspeção médico-escolar o governo mandara observar, no Rio e em São Paulo, "nas differentes repartições a marcha e a orientação dos trabalhos" (ano 1, v. 1, p. 5). 
4 A inspeção médico-escolar foi criada no Brasil em 1889, pelo então ministro do Império Conselheiro A. Ferreira Vianna, como "inspeção higiênica dos estabelecimentos públicos e particulares de instrução e educação" do Rio de Janeiro, funcionando por meio de uma comissão permanente sob orientação do inspetor geral de higiene professor Rocha Faria, que teria expedido instruções minuciosas e mandado visitar estabelecimentos de ensino (BASILE, 1920, p. 81).

5 Entre as obras referentes à inspeção médico-escolar existentes na biblioteca da Inspetoria do Ensino podia-se encontrar A inspeção escolar, de Basile, e Noções de bygiene, de Afrânio Peixoto.

6 O exame, pensado em termos de formação de saberes e exercício do poder, foi discutido por Foucault em Vigiar e punir.

7 "Beethoven avec ses otites précoces, et son perpétuel état de morbidité, d'une part, l'exaltation de la pensée et son enórme puissance de travail d'autre part, constitue bien le type de l'hérédo". Audrain-"La Syphilis Obscure" [...] “Victima innocente da culpa paterna, Beethoven, entretanto, fôra em toda a sua vida casto e impolluto!” (O Ensino, ano 1, n. 1, 1922, p. 17-18).

8 O médico Renato Kehl, um dos mais importantes divulgadores da eugenia no Brasil, foi fundador da primeira Sociedade de Eugenia em São Paulo (1918); criou ainda a Comissão Central de Eugenia, no Rio de Janeiro, em 1931.

9 Vigiar casamentos e a imigração eram medidas de controle sobre a população. Ver "Os controles reguladores sobre os processos biológicos: o corpo - espécie”, em A medicalização da raça: médicos, educadores e discurso engênico.

10 Consultar Vera Regina Beltrão Marques. A espécie em risco: a sífilis no Paraná nos anos 1920, em Dilene Raimundo do Nascimento \& Diana Maul de Carvalho (Orgs). Uma história brasileira das doenças.

11 Os imigrantes que no Paraná chegaram vinham colonizar, ocupar a terra, produzindo para a subsistência e o abastecimento, pois, em meados do século XIX, houvera importante crise de gêneros de primeira necessidade. Ingleses, alemães, italianos, polacos, entre outros aqui se estabeleceram. Ver Westphalen, Machado e Balhana (1968).

12 A educação é a salvadora, apregoava Kehl. Os mestres deveriam semanalmente dedicar alguns minutos a uma preleção contra o álcool ou as doenças como sífilis, tuberculose, opilação, impaludismo ou lepra. Ver Lições de engenia, p. 46-48.

13 Mario Gomes, em "Triste caso", publicado em O Ensino (jan.1924), discorre sobre o atendimento que prestou a um casal de noivos: ele, magro e feio, com faces características de um imbecil; ela, esbelta, tez rosada, aparentando robustez e saúde, porém heredo-sifilítica. Pronunciou-se enfaticamente em condenar o casamento pretendido por ambos, pois, como aludiu, "parece-me ter chegado ou já passado o momento em que é preciso por cobro a essas desgraças; é indispensavel que os responsáveis pelo futuro da raça, os governos, os paes, os medicos, levantem em unisono o clamor que existe latente em todos nós, contra o casamento de enfermos e degenerados!” Já Renato Kehl, em Lições de engenia (p. 170), considerava que os cegos, surdos (congênitos ou hereditários), tarados ou epiléticos deveriam ser esterelizados, a bem de preservarem-se de uma prole degenerada. 
14 A cruzada contra a tuberculose manter-se-á nos anos 1930 com toda a intensidade e os médicos paranaenses permanecerão clamando aos pais que não contaminem seus filhos com o "germe da peste branca, que lhes mata os filhos pequeninos", conforme palavras do Dr. Homero Braga (Revista Médica do Paraná, n. 10, 1933, p. 316).

15 Os caboclinhos brasileiros dividiram com o Jeca Tatu - personagem de Monteiro Lobato - a representação do brasileiro indolente e atrasado da "roça", depois redimido quando Lobato se insere na campanha pelo saneamento. Em carta a Lellis Vieira, diz que "Urupês... é a vidinha da roça, como a vi e como senti em 7 anos que passei enterrados na Mantiqueira. O que você e outros gostaram foi da espontaneidade sem arrebiques nem falsificações com que as coisas, os tipos e paisagens são narrados". Ver: IEL/ CEDAE/ UNICAMP - Fundo MLB - série correspondência ativa. Transcrição da carta de Monteiro Lobato a Lellis Vieira, 1918 (?). Monteiro acabaria descobrindo que o Jeca não era preguiçoso, mas doente, um opilado. A Liga Pro-Saneamento do Brasil, inspirada na obra de Belisário Penna, obra essa "recusada por todos os editores desta capital", foi dada à divulgação pelos médicos Olympio Barreto e Plínio Cavalcanti. Lobato receberia de Cavalcanti o convite para participar como membro da delegação da Liga, em São Paulo. Fundo MLB - série correspondência passiva, pasta 21.

16 Consultar: Absolvido pela medicina: o Brasil descoberto pelo movimento sanitarista da Primeira República, de Nísia Lima e Gilberto Hochman, e Anos 1910: educação e saúde para formar o povo brasileiro, de Liane Bertucci.

17 O caboclo paranaense certamente resultou da mistura das três raças, porém, nos inícios do Novecentos, encontrava-se bastante embranquecido. Embora algumas cidades paranaenses tivessem alcançado maiores concentrações de escravos, no século XIX há mudanças importantes. "O declínio econômico dos Campos Gerais e os altos preços alcançados pelos escravos na lavoura cafeeira, provocados pela proibição do tráfico, estimulariam a transferência de uma grande parcela de escravos para São Paulo, alterando o panorama demográfico paranaense" (PEREIRA, 1996, p. 58).

18 Ver A inspeção médico-escolar no Paraná dos anos 1920: o apostolado de médicos e professores de Vera R. B. Marques e Fabiana C. S. de Ávila Farias.

Recebido: 27/10/2009

Aprovado: 25/11/2009

Contato:

Universidade Federal do Paraná

Setor de Educação

Departamento da Teoria e Fundamentos da Educação

Rua General Carneiro, 460 - $5^{\circ}$ andar

Centro

CEP 80060-150

Curitiba/PR 